\title{
An Intelligent Fuzzy Logic Based Greenhouse System Modeling for the Antalya Area
}

\author{
Ahmet Erkam Karaburun, Utku Köse
}

\begin{abstract}
The place of the Turkish agricultural sector in world agriculture is very important. Many different activities focused on agriculture are widely carried out in Turkey. Greenhouse cultivation, which is one of these fields of activity, is also very popular in and around Antalya province. Undoubtedly, it is necessary to cope with various environmental conditions in order to carry out greenhouse activities in a healthy way. Based on the explanations, the aim of this study is to design an intelligent control system that aims to provide the optimum greenhouse environment against the conditions that adversely affect greenhouse cultivation. In line with this purpose, the Fuzzy Logic technique of Artificial Intelligence was used in order to obtain a practical and fast system. The preliminary findings regarding the designed system were evaluated under this study.
\end{abstract}

Index Terms - Intelligent greenhouse system, fuzzy logic, artificial intelligence, agricultural technology, intensive farming.

\section{INTRODUCTION}

It is obvious that the agricultural sector always be important for humanity. The regions in the world where the climate is favorable have always been valuable for agriculture. Anatolia has been one of these valuable agricultural areas throughout history. Although the Turkish agricultural sector is suitable for agricultural areas and climatic conditions, its economic return remains below the expected level in agriculture compared to developed countries. No matter how good the conditions in agriculture are, product productivity does not reach the desired levels with extensive farming approaches [1]. In intensive farming approaches, where technology and scientific data are used more, the productivity per square meter is quite high compared to extensive agriculture. In this context, greenhouse cultivation is one of the intensive farming techniques currently being used in Turkey $[1,2]$.

Although greenhouse activities are more productive than the crops grown in an extensive agricultural environment, drastic changes in climatic conditions can negatively affect greenhouse activities. One of the most important problems in greenhouse cultivation is keeping the ambient conditions at an optimum level. Although there are some interventions by humans to keep the ambient conditions at optimum levels; The instantaneous and consistent nature of these interventions is always open to discussion. These interventions therefore need to be placed in a logical framework, taking into the some factors. A machine-based system should be put forward to

Ahmet Erkam Karaburun, Department of Computer Engineering, Suleyman Demirel University, Isparta, Turkey

Utku Kose, Department of Computer Engineering, Suleyman Demirel University, Isparta, Turkey fulfill the mentioned interventions. Thus, a consistent solution that goes beyond human competencies will be revealed. A possible machine-based solution should be associated with a system that includes intelligent control-oriented evaluations rather than routine interventions to ensure maximum performance. While providing intelligent control, it is important to set up the system that is practical to use and works quickly.

The aim of this study is based on the modeling of an intelligent control system based on the explanations. In the study, it was aimed to keep the greenhouse environment at optimum values, especially in the greenhouse activities of the Mediterranean Region Antalya province. Accordingly, it is aimed to interpret the greenhouse ambient conditions (temperature, humidity, soil moisture, amount of light) by the system with the Fuzzy Logic technique. The greenhouse environment will be controlled with fuzzy outputs produced by using fuzzy input values. With this method, an Artificial Intelligence-based intelligent greenhouse system has been designed, which is practical to install and implement, advantageous in speed, and aims for early warning and unmanned intervention. The hardware base of the system will be established in future studies, and within the scope of this study, the software-oriented state of the system was pre-assessed and discussed.

In line with the subject and aims of the study, the following parts of the text are organized as follows: In the next section, agriculture in the world and in Turkey, which is the basis of the study, is discussed and information on greenhouse activities is presented. Then, the Fuzzy Logic technique, which forms the basis of the intelligent system, and the system established with the said technique are explained in the third and fourth sections, respectively. Following the relevant sections, the feedbacks received by modeling in the MATLAB environment regarding the system established under the fifth section were evaluated and these feedbacks were compared with the results of the Fuzzy Logic algorithm developed on the NumPy library of the Python programming language. The study is concluded with the last section, where the general conclusions and future studies are discussed.

\section{AGRICULTURE IN THE WORLD AND TURKEY}

Agriculture has had an indispensable place for human beings throughout history. People have made an effort to dominate fertile agricultural areas due to both the continuation of their biological existence and economic reasons. Although the agricultural sector, which has a history of thousands of years, seems to lag behind other sectors in terms of economic value after the development of technology and the formation of different business lines, it is still important for humanity. At 
this point, it is necessary to deal with agriculture in the world and in Turkey in order to understand the importance of the subject and to connect with the problem of the study.

Submit your manuscript electronically for review.

\section{A. Agriculture in the World}

Countries such as Germany, the USA, the Netherlands, China, Canada and France, which are among the economically developed countries of the world, obtain large incomes from agricultural production and exports Table I. The total income of the top 10 countries corresponds to $48 \%$ of the world total [3].

TABLE I. World Agricultural Export Data for 2017 [3]

\begin{tabular}{|c|c|c|c|c|}
\hline Countries & \multicolumn{4}{|c|}{ Export, Billion \$ } \\
\hline & 1995 & 2005 & 2010 & 2017 \\
\hline World & 360. & 539. & 876. & $1,167.4$ \\
& 9 & 5 & 6 & 0 \\
\hline USA & 42.2 & 48.5 & 82.6 & 103 \\
\hline Netherlands & 34.1 & 42.7 & 66 & 90.4 \\
\hline China & 10 & 22.5 & 41.1 & 63.6 \\
\hline Germany & 21.2 & 35.2 & 55.2 & 65.4 \\
\hline Brazil & 10 & 21.8 & 45.2 & 48 \\
\hline France & 30.3 & 32.9 & 43.8 & 44.1 \\
\hline Spain & 11.5 & 21.8 & 29.9 & 41.3 \\
\hline Canada & 11.7 & 20.7 & 28.5 & 37.4 \\
\hline Belgium & 11.5 & 23.6 & 31.3 & 36.6 \\
\hline Italy & 11.2 & 12.4 & 23.9 & 29.8 \\
\hline Thailand & 10.7 & 12.4 & 23.9 & 29.8 \\
\hline Argentina & 7.2 & 12.4 & 22.4 & 25.8 \\
\hline India & 5.4 & 8 & 15.5 & 30.4 \\
\hline Turkey & 3.4 & 6.5 & 10.5 & 14.3 \\
\hline Others & 140. & 218. & 356. & 507.5 \\
& 5 & 1 & 8 & \\
\hline
\end{tabular}

As can be seen from Table 1, countries with high agricultural returns are those that are technologically advanced or that use advanced agricultural approaches and techniques. As the solutions used improve, the yield and quality per unit area increases and this increase returns to the country economically.

\section{B. Agriculture in Turkey}

Turkey is a geography with abundant water resources, favorable climatic conditions and agricultural production for thousands of years. Agriculture in Anatolia has been done for many years using human and animal power. Especially in the 1900 s, with the start of the use of machinery in agriculture and its spread in the following years, more land was cultivated and there was an increase in agricultural production. Today, approximately 23 million hectares of 78 million hectares of land within the borders of Turkey is agricultural land. In other words, approximately $30 \%$ of Turkey is considered as agricultural land [2]. In recent years, agriculture has developed with intensive techniques and the production of agricultural products with high economic value has increased. Greenhouse activities had a large share in this increase. For example, banana, a tropical climate fruit whose homeland is South East Asia, can be grown in Turkey by greenhouse cultivation activities by providing suitable climatic conditions.
Again, tomato is another transfer plant that has an important place in the Mediterranean Region Agricultural activities, although its natural environment is Central and South America.

\section{Greenhouse in Turkey and the Situation of Antalya Environment}

Greenhouse activities in our country first started in the 1940 s with the support of state institutions, and then developed in the Mediterranean and Aegean Regions. The region where greenhouse activities are still carried out intensively is the Mediterranean Region. The reason for this is entirely related to the climate. Both the long sunshine duration and the low winter temperatures (rarely below 0 Celsius) are the most important reasons for the development of the greenhouse sector in this region. Mediterranean Region greenhouse activities alone constitute $86 \%$ of greenhouse-oriented agricultural activities in Turkey. As can be seen from Table II, which shows the distribution of greenhouse cultivation in Turkey in 2019, greenhouse activities are concentrated in and around Antalya province [2].

TABLE II. Distribution of Turkey's Greenhouse Activities in 2019 by Provinces

\begin{tabular}{|c|c|c|c|}
\hline Provinces & $\begin{array}{c}\text { Greenhouse } \\
\text { Area (decare) }\end{array}$ & Provinces & $\begin{array}{c}\text { Greenhouse } \\
\text { Area (decare) }\end{array}$ \\
\hline Antalya & 286.522 & Aydın & 12.717 \\
\hline Mersin & 201.060 & Hatay & 11.456 \\
\hline Adana & 160.493 & Burdur & 9.843 \\
\hline Mugla & 39.048 & Isparta & 4.942 \\
\hline İzmir & 14.016 & Amasya & 4.881 \\
\hline
\end{tabular}

The presence of greenhouse oriented agriculture has reached 789,604 decares in Turkey as of 2019. Turkey with these figures; It is among the first five countries in the world and among the first two countries in Europe. The value of greenhouse agriculture in Turkey is approximately 1,1 billion $\$[4]$.

The distribution of products produced in greenhouse activities is as follows: 94\% Vegetables, 5.5\% Fruit, $0.5 \%$ Ornamental Plants. Among the values expressed, tomato is in the first place with a share of $49 \%$, cucumber is in the second place with $14 \%$ and watermelon is in the third place with $10 \%$ [1]. Greenhouses in Kınık territory in Kaş district of Antalya are shown in Figure 1.

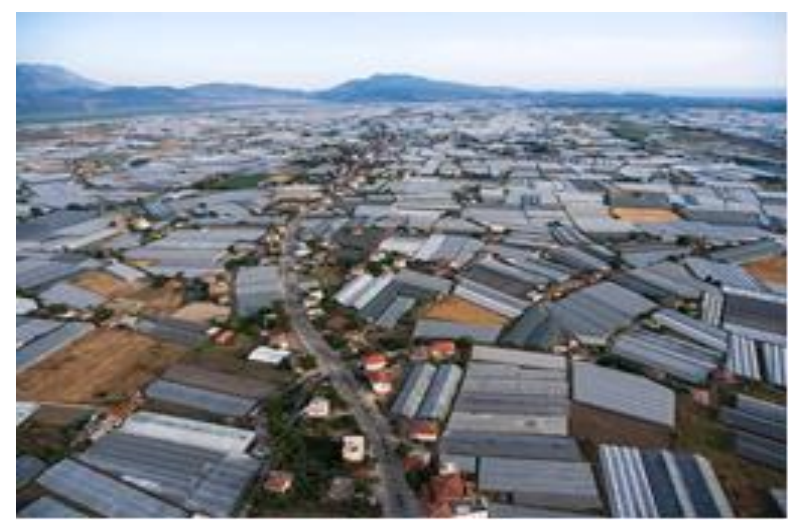

Figure 1. Greenhouses in Kınık Territory in Kaş District of Antalya [5] 
When evaluated in general, it is extremely important that greenhouse activities, which have such a critical value in terms of agricultural activities in Turkey, can be kept at stable levels and that negative factors are eliminated whenever possible. In this study, a system was developed based on this approach.

\section{FUZZY LOGIC}

The foundations of fuzzy logic, one of the widely used artificial intelligence techniques, were first introduced by Lütfü Asker Zadeh under Fuzzy Set Theory [6]. Fuzzy logic, which is based on Fuzzy Set Theory, can describe relations between concepts in a quantitative way, in membership degrees between 0 and 1, unlike classical logic. The main idea that allows fuzzy logic to be developed from Fuzzy Set Theory is to create a conceptual framework for verbally represented knowledge [7]. In this context, the evaluations expressed as "true" and "false" in classical logic can have intermediate evaluations in fuzzy logic. In this case, it corresponds to expressing changing conditions in human language, just as in real life. From a mathematical point of view, a variable can be found in more than one set in Fuzzy logic, and values called 'membership degrees' are used to describe this membership status [8]. The degree of membership can also be defined by a generalized function defined as the membership function. Accordingly, as shown in Equation 1, $\mathrm{U}$ is a general set and $\mathrm{A}$ is defined as a fuzzy subset of $\mathrm{U}[9,10]$.

$$
\mu A(u): U \rightarrow[0,1]
$$

Some other assumptions about inferences in fuzzy logic are as follows $[10,11]$. Let two subsets be defined as sets A and B within the universal set $\mathrm{U}$. For fuzzy sets $\mathrm{A}$ and $\mathrm{B}$ to be equal, the formula should be as follow in Equation 2:

$$
\forall u \in U: \mu A(u)=\mu B(u)
$$

For A to be a subset of B the formula should be as follow in Equation 3:

$$
\forall u \in U: \mu A(u) \leq \mu B(u)
$$

Properties of intersection and union operations of two related sets membership function $\mu \mathrm{A} \cap \mathrm{B}(\mathrm{u})$ of $\mathrm{A} \cap \mathrm{B}$ for $\forall \mathrm{u} \in$ $\mathrm{U}$ the formula as can be write follow in Equation 4:

$$
\mu A \cap B(u)=\min \{\mu A(u), \mu B(u)\}
$$

For $\forall \mathrm{u} \in \mathrm{U}$, the membership function $\mu \mathrm{AU}$ B(u) of AU B is written as in Equation 5:

$$
\mu A \cup B(u)=\max \{\mu A(u), \mu B(u)\}
$$

For $\forall \mathrm{u} \in \mathrm{U}, \mu \mathrm{A} 1(\mathrm{u})$ is the membership function is written as in Equation 6:

$$
\mu A 1(u)=1-\mu A(u)
$$

\section{A. Fuzzy Logic Controller}

The most important approach in which the fuzzy logic technique comes to life in real world problems is the fuzzy logic controller. Fuzzy logic controller is an intelligent controller system that consists of three basic parts: fuzzification, rule-based inference mechanism and defuzzification [11]. The fuzzy logic controller system structure is shown in Figure 2.

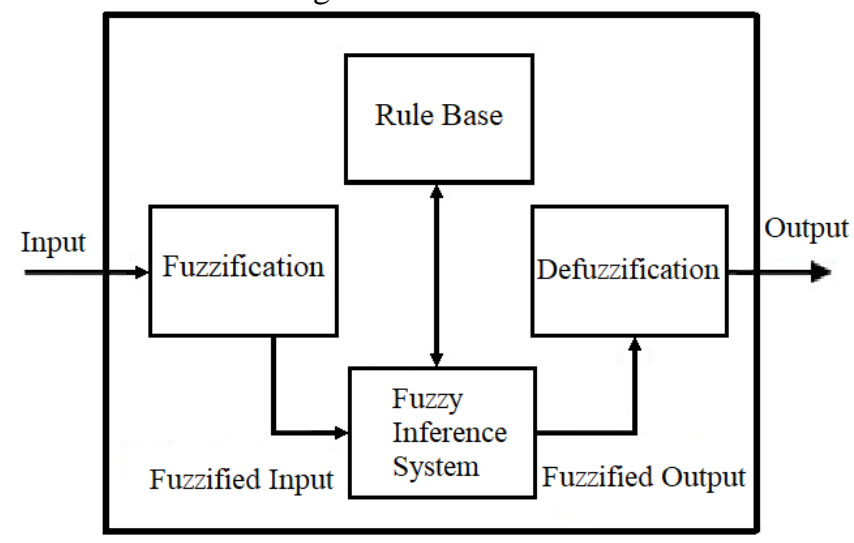

Figure 2. The fuzzy logic controller system structure

If we examine the rule-based inference mechanism under two sub-components as the rule base and the inference unit, we can see that there are 4 different mechanisms in total. These mechanisms are briefly as follows [12-14]:

Fuzzification: This is the part where input information is converted into linguistic expressions. While this transformation is being done, the transformation should be done by experts who have experience in the subject [14].

Rule Based Inference Unit: This unit contains all of the logical rules and functions written in the if-then type to deliver the input values to the output. For example, if $R I={ }^{\prime} X=a l$ and $Y=b 1$ then $Z=c 1^{\prime}$; If $R 2={ }^{\prime} X=a 2$ and $Y=b 2$ then $Z=c 2^{\prime}$ rules can be written.

Defuzzification: After passing the input variables through the rule-based inference unit, it is possible to describe the whole effect of the rules with an expression like, in Equation 7:

$$
R_{1}+R_{2}+R_{3}+\ldots+R_{n}=\sum_{i=1}^{n} R_{i}
$$

There is no (+) addition operation here, but the expression of the rules corresponds to a combination operation in which all the rules in the form of $R_{1}, R_{2}, \ldots, R_{n}$ are valid.

According to the clarification methods from the result set obtained by processing the rules in the defuzzification process, fuzzy logic output methods such as the average of the maximum, the largest of the maximum, and the smallest of the maximum have been developed [15].

\section{FuZZY LOGIC BASED INTELLIGENT GREENHOUSE SYSTEM}

The aim of developing the system modeled in this study for greenhouse activities is by adjusting the environment in cases where environmental conditions are far from optimum values; to improve the living standards of plants, to increase productivity and to prevent material and moral losses in this direction. The general logic of the system can be briefly expressed as follows: The modeled system receives ambient values through sensors. The received values are used as input data in fuzzy logic controllers. Output data is obtained according to the created rule base.

Three different fuzzy controllers were used in the designed 
smart greenhouse system. The fuzzy logic controllers used are: Fuzzy logic ventilation controller, Fuzzy logic irrigation controller and Fuzzy logic shading controller.

Fuzzy Ventilation System: In the fuzzy ventilation system, the input parameters are determined as temperature Celsius $\left({ }^{\circ} \mathrm{C}\right)$ and ambient humidity as relative humidity $(\%)$. It is used as how much the window angle will be opened (\%) in the unit of the output parameter.

Fuzzy Irrigation System: Ambient humidity (\%) and soil moisture $(\%)$ are used as input data, and the operating performance of the water engine (\%) is used as output data.

Fuzzy Shading System: ambient light value siemens (S) and temperature Celsius $\left({ }^{\circ} \mathrm{C}\right)$ input data, how much to open the curtain to be used for shading (\%) output data.

\section{A. Fuzzy Logic Design with MATLAB}

In order to apply fuzzy logic in the developed system, the input and output variables of the system must be determined. The fuzzy inference scheme designed in the MATLAB environment for the intelligent greenhouse system developed in this context is shown in Figure 3.

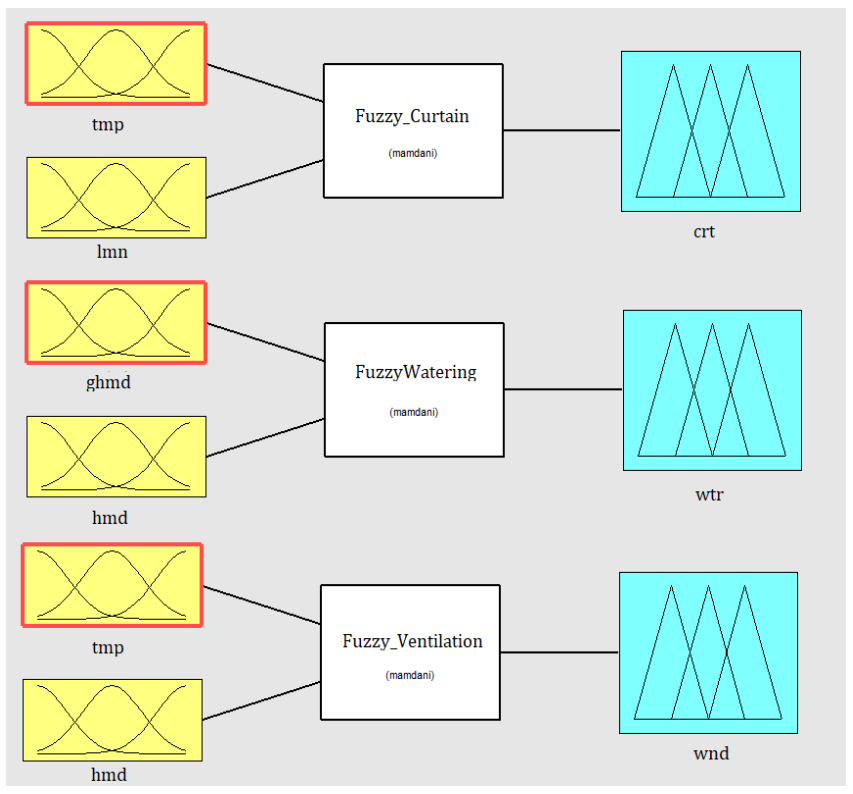

Figure 3. MATLAB system image of fuzzy controllers

While naming membership functions in the fuzzy ventilation system, "hmd" for ambient humidity, "tmp" for temperature and "wnd" for window angle are used. In the fuzzy irrigation system, the names "hmd" for ambient humidity, "ghmd" for soil moisture and "wtr" for irrigation are made. In the fuzzy shading system, this nomenclature is determined as "lmn" for ambient light value, "tmp" for temperature and "crt" for curtain output. The input membership functions of the system are given in Figure 4.

In the process of designing the said membership functions, the climatic conditions of the province of Antalya were taken into account.

After determining the input, output variables and membership functions, 25 rules were determined for each controller in order to find the output of the system. If we examine an example rule for a fuzzy ventilation system: If (tmp is LOW) and (hmd is MEDIUM) then (wnd is LOW). The clear expression of this rule can be expressed as when "the temperature is low" and "the humidity is medium" than "the window angle is low".

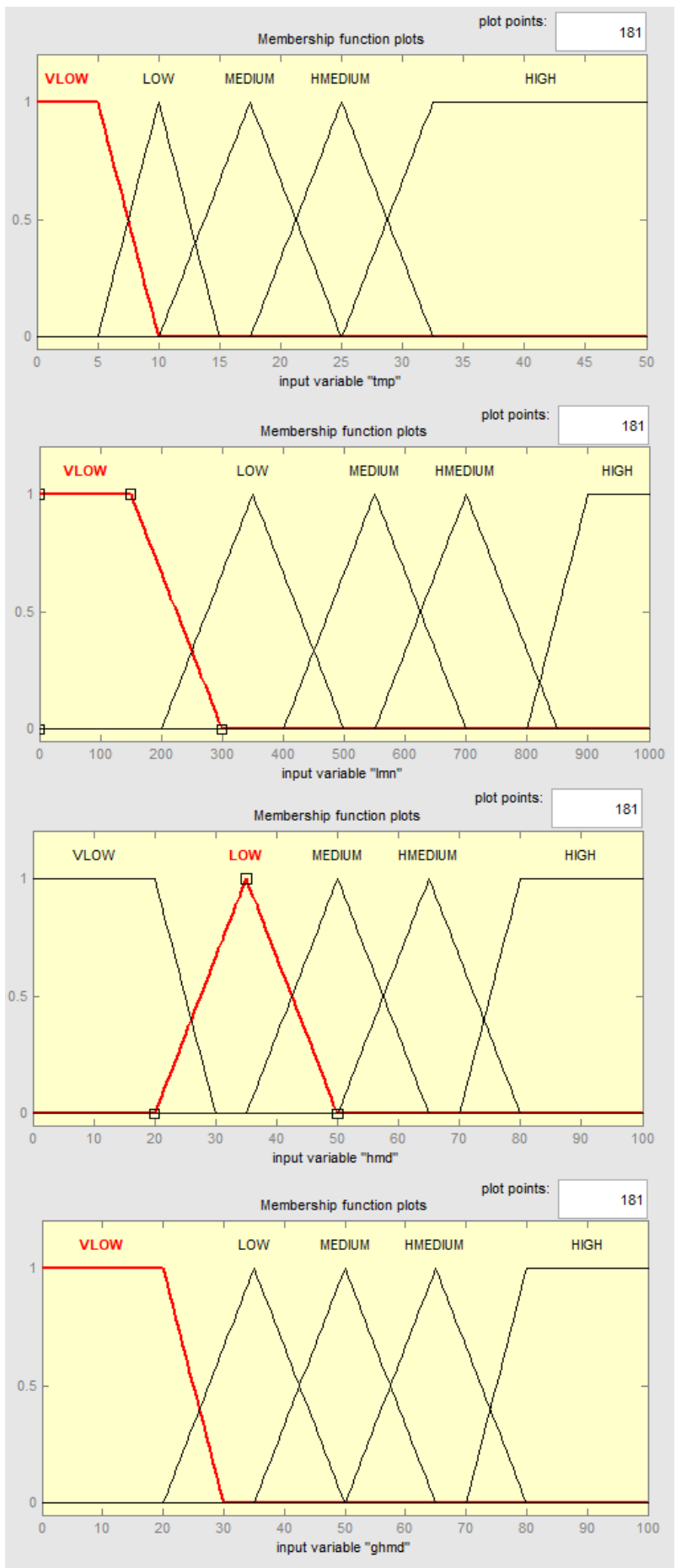

Figure 4. The input membership functions of the fuzzy system

The output membership function of the system is shown in Figure 5. 
International Journal of Engineering and Applied Sciences (IJEAS) ISSN: 2394-3661, Volume-8, Issue-6, 2021

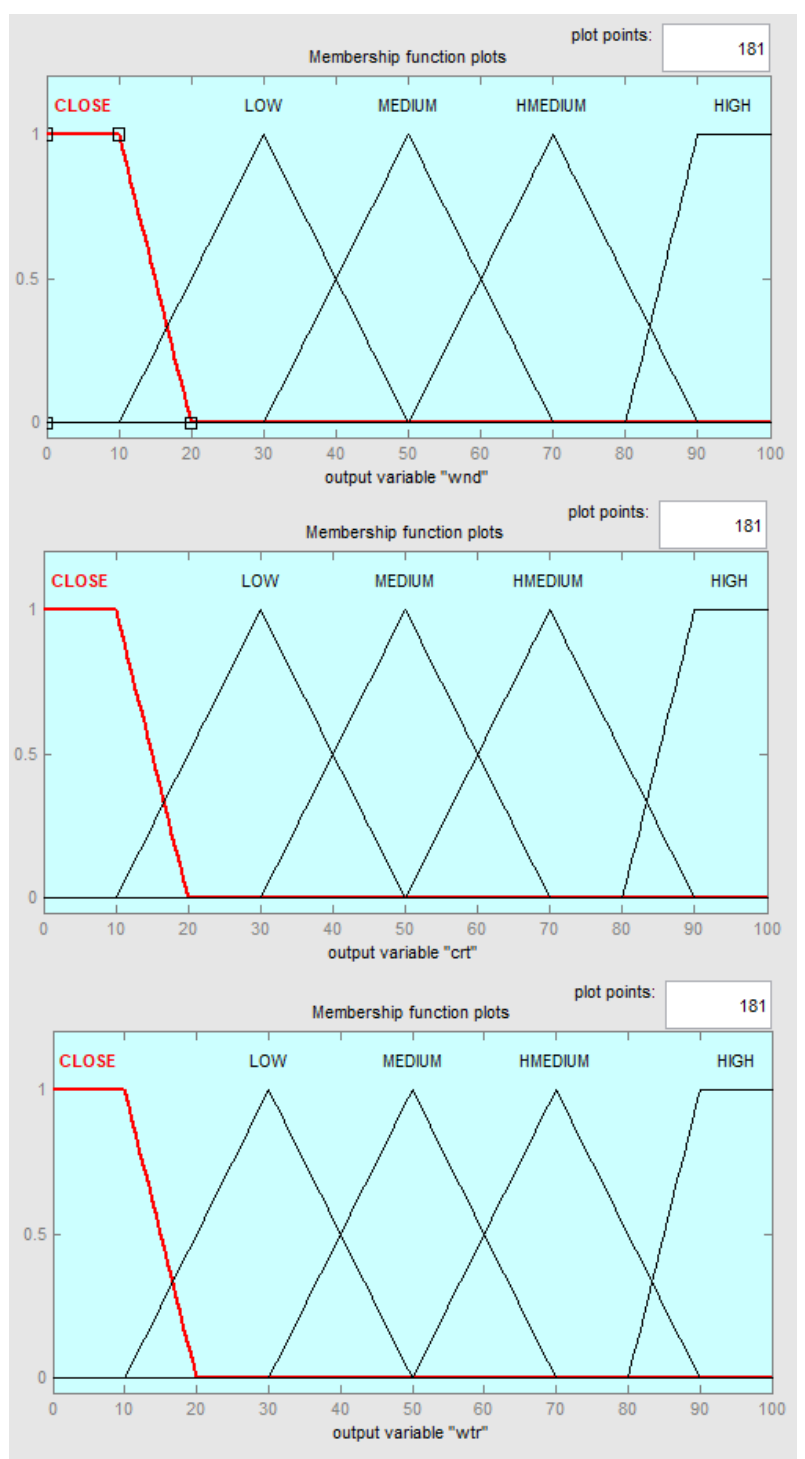

Figure 5. The output membership functions of the fuzzy system

In fuzzy logic controllers designed with MATLAB, impact of different input values on output values are shown in Table III.

TABLE III. IMPACT OF DIFFERENT INPUT VALUES ON OUTPUT VALUES

\begin{tabular}{|c|c|c|}
\hline \multicolumn{2}{|c|}{ Inputs } & Output \\
\hline Temperature & Humidity & $\begin{array}{c}\text { Window } \\
\text { Angle Ratio }\end{array}$ \\
\hline $24,1^{\circ} \mathrm{C}$ & $\% 48,6$ & $66,9 \%$ \\
\hline $14,2^{\circ} \mathrm{C}$ & $\% 33,8$ & $45,3 \%$ \\
\hline $6,1^{\circ} \mathrm{C}$ & $\% 55,3$ & $17,3 \%$ \\
\hline $\begin{array}{c}\text { Soil } \\
\text { Moisture }\end{array}$ & Humidity & $\begin{array}{c}\text { Water } \\
\text { Pump }\end{array}$ \\
\hline$\% 35,2$ & $\% 48,4$ & $\% 68,9$ \\
\hline$\% 78,2$ & $\% 22,4$ & $\% 13,7$ \\
\hline$\% 12,5$ & $\% 52,8$ & $\% 70$ \\
\hline
\end{tabular}

\begin{tabular}{|c|c|c|}
\hline Temperature & $\begin{array}{c}\text { Light } \\
\text { Value }\end{array}$ & $\begin{array}{c}\text { Curtain } \\
\text { Angle Ratio }\end{array}$ \\
\hline $24,1^{\circ} \mathrm{C}$ & $750 \mathrm{~S}$ & $66,6 \%$ \\
\hline $14,2^{\circ} \mathrm{C}$ & $400 \mathrm{~S}$ & $27,4 \%$ \\
\hline $6,1^{\circ} \mathrm{C}$ & $100 \mathrm{~S}$ & $7,95 \%$ \\
\hline
\end{tabular}

The effect of all inputs on the outputs in the fuzzy system is shown in Figure 6.

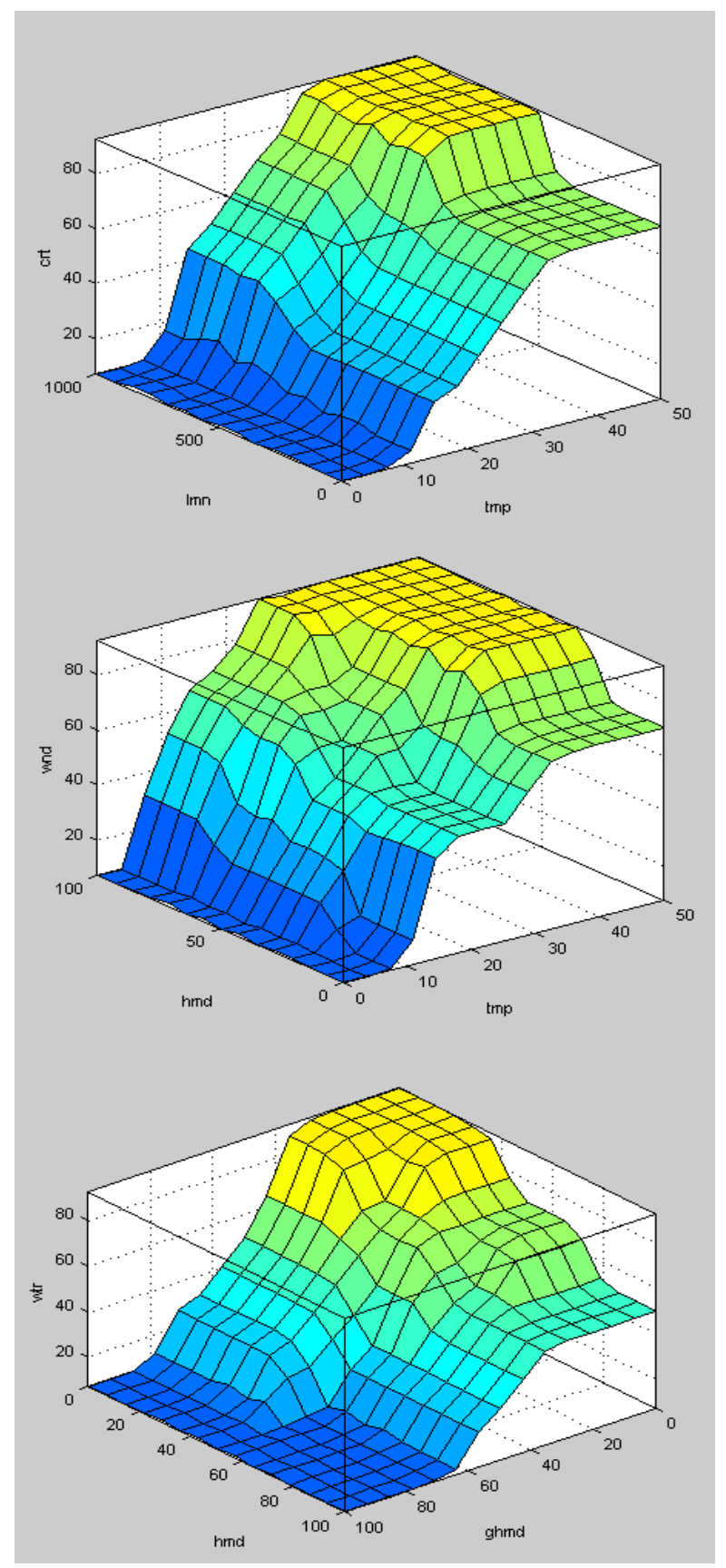

Figure 6. The effect of all inputs on the outputs in the fuzzy system

\section{B. Fuzzy Logic Design with Python}

The designed fuzzy model has been implemented using the "numpy" library in Python with the same features, and the input membership functions of the system are shown in Figure 7. 


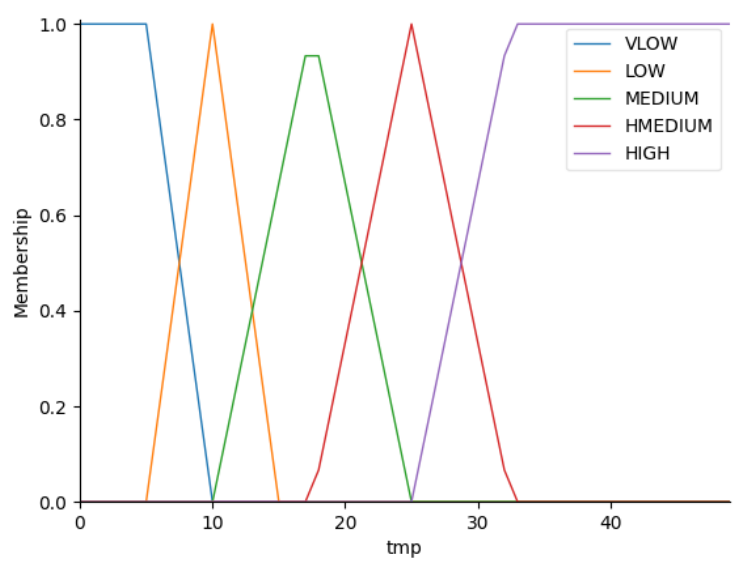

system

The python output membership functions of the fuzzy system are shown in Figure 8.
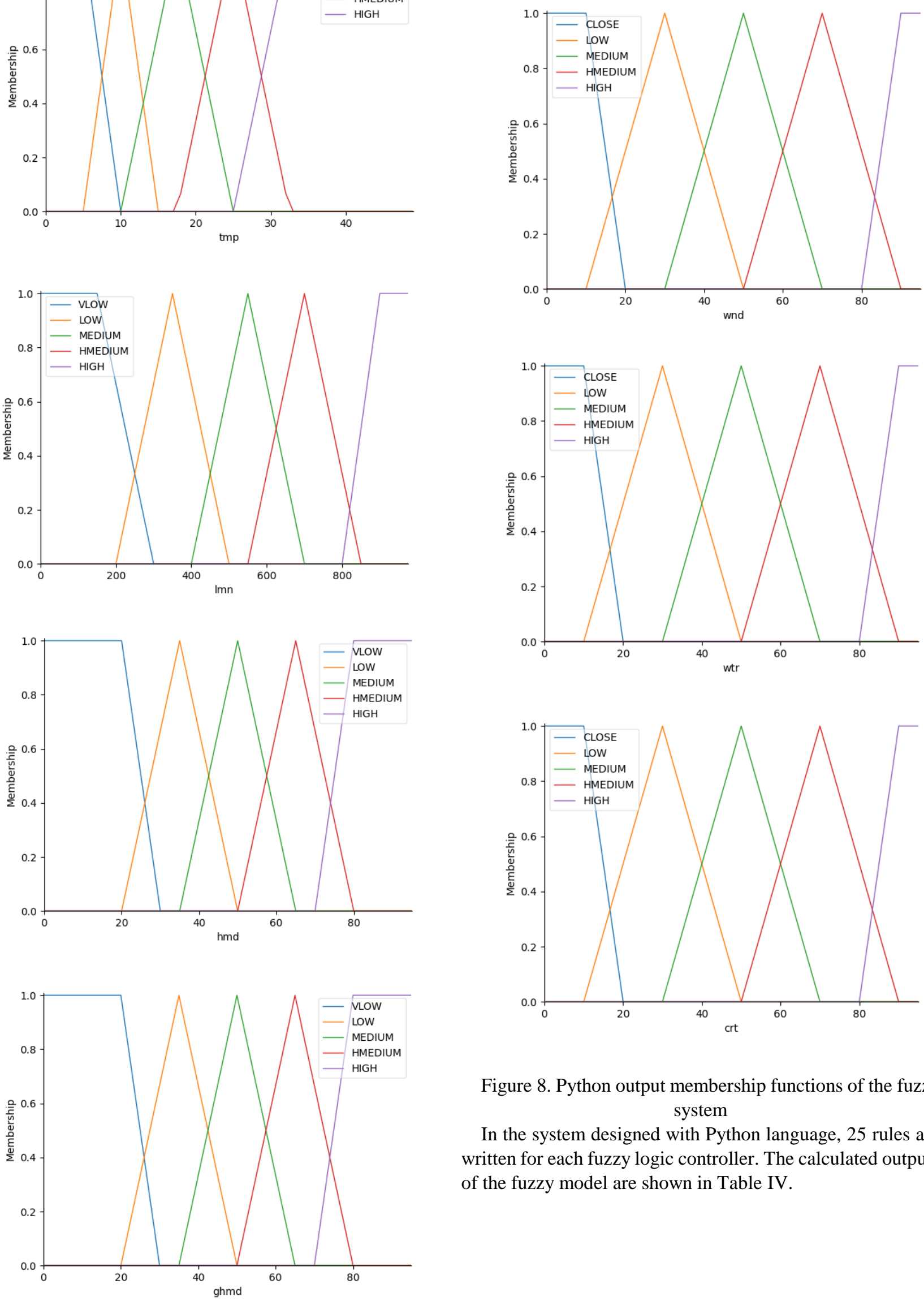

Figure 8. Python output membership functions of the fuzzy system

In the system designed with Python language, 25 rules are written for each fuzzy logic controller. The calculated outputs of the fuzzy model are shown in Table IV.

Figure 7. Python input membership functions of the fuzzy 
TABLE IV. IMPACT OF DIFFERENT INPUT VALUES ON OUTPUT VALUES

\begin{tabular}{|c|c|c|}
\hline \multicolumn{2}{|c|}{ Inputs } & Output \\
\hline Temperature & Humidity & $\begin{array}{c}\text { Window } \\
\text { Angle Ratio }\end{array}$ \\
\hline $24,1^{\circ} \mathrm{C}$ & $\% 48,6$ & $\% 66,77$ \\
\hline $14,2^{\circ} \mathrm{C}$ & $\% 33,8$ & $\% 45,2$ \\
\hline $6,1^{\circ} \mathrm{C}$ & $\% 55,3$ & $\% 17,68$ \\
\hline $\begin{array}{c}\text { Soil } \\
\text { Moisture }\end{array}$ & Humidity & $\begin{array}{c}\text { Water } \\
\text { Pump }\end{array}$ \\
\hline$\% 35,2$ & $\% 48,4$ & $\% 68,92$ \\
\hline$\% 78,2$ & $\% 22,4$ & $\% 14,0$ \\
\hline$\% 12,5$ & $\% 52,8$ & $\% 70,0$ \\
\hline Temperature & $\begin{array}{c}\text { Light } \\
\text { Value }\end{array}$ & $\begin{array}{c}\text { Curtain } \\
\text { Angle Ratio }\end{array}$ \\
\hline $24,1^{\circ} \mathrm{C}$ & $750 \mathrm{~S}$ & $\% 66,0$ \\
\hline $14,2^{\circ} \mathrm{C}$ & $400 \mathrm{~S}$ & $\% 27,0$ \\
\hline $6,1^{\circ} \mathrm{C}$ & $100 \mathrm{~S}$ & $\% 8,0$ \\
\hline
\end{tabular}

\section{CONCLUSION AND FUTURE WORKS}

In this study, a fuzzy logic model was designed based on the greenhouse activities of the Turkish agricultural sector in the Mediterranean Region and especially around the province of Antalya.

While the system was being developed, it was aimed to improve the living standards of the plants, to increase the yield and to prevent material and moral losses in this direction by keeping the greenhouse environmental conditions within the appropriate values. In this context, a fuzzy logic-based intelligent system model was introduced in MATLAB and Python, and a total of 75 rules were determined for both systems. Input parameters in the model were determined as temperature, humidity, light value and soil moisture. Window angle ratio for fuzzy ventilation system, water pump performance for fuzzy irrigation system, curtain angle ratio for fuzzy shading system were used as output parameters. Trimf and trapmf membership functions are used in both systems. It has been observed that the system outputs are quite similar.

In this study, it is revealed how the fuzzy logic oriented system can be modeled easily. Within the scope of future studies, it will be focused on the realization of Raspberry Pi, Arduino and similar electronic mechanisms. Since the designed system is planned to be compiled and run in real time, it is thought that it would be more appropriate to implement it with the Python programming language on a Raspberry Pi computer.

\section{REFERENCES}

[1] Turkish Statistical Institute, 2019

[2] Republic Of Turkey Ministry Of Agriculture And Forestry, 2019. https://www.tarim.gov.tr/Konular/Bitkisel-Uretim/Tarla-Ve-Bahce-Bi tkileri/Ortu-Alti-Yetistiricilik.
[3] Konoema, World Exports and Imports of Agricultural products, https://knoema.com/cduhihd/world-exports-and-imports-of-agricultur al-products, 2018.

[4] Republic Of Turkey Ministry Of Agriculture And Forestry, 2020 https://www.tarim.gov.tr/Konular/Bitkisel-Uretim/Tarla-Ve-Bahce-Bi tkileri/Ortu-Alti-Yetistiricilik.

[5] Antalya-Kınık Local News Agency, 2018.

[6] L.A. Zadeh, Fuzzy Sets, Information and Control, 8, 338-353, 1965

[7] P. Mahönen, T. Frantti, Fuzzy classifier for star-galaxy separation, The Astrophysical Journal, 541(1): 261-263, 2000.

[8] U.Köse, O.Deperlioglu, An Educational, Virtual Laboratory System for Fuzzy Logic, 1st International Symposium on Computing in Science \& Engineering, June 3-4, Kusadasi, Aydin, Turkey pp. 1335-1342, 2010 http://iscse2010.gediz.edu.tr.

[9] N. K. Kasabov, Foundations of Neural Networks, Fuzzy Systems and Knowledge Engineering, ISBN 0-262-11212-4, 1998.

[10] B. Kosko, Neural Networks and Fuzzy Systems, Prentice Hall, ISBN 0-13-611435-0, 1992

[11] M. S. Anand, B. Tyagi, Design and Implementation of Fuzzy Controller on FPGA, International Journal of Intelligent Systems and Applications, 4(10), 35-42, 2012

[12] P. Dadone, Design Optimization of Fuzzy Logic Systems, Doctor of Philosophy in Electrical Engineering, Virginia Polytechnic Institute and State University, 2001.

[13] M. J. Mendel, Fuzzy Logic Systems for Engineering: A Tutorial, Proceedings of the IEEE,83(3), 1995.

[14] S. Kutuva, N.P. Reddy, Y. Xiao, X. Gao, S.I. Hariharan, and S. Kulkarni, A novel and fast virtual surgical system using fuzzy logic, In Proceedings of the IADIS Virtual Multi Conference on Computer Science and Information Systems, 15-19 May, IADIS, 2006.

[15] I.H. Altas, Bulanık Mantık: Bulanık Denetim, Enerji, Elektrik, Elektromekanik-3e, vol.64, pages:76-81, Bilesim Yayınc1lık A.Ş., Istanbul, September, 1999.

Ahmet Erkam Karaburun is currently a master student at Suleyman Demirel University in Turkey. He graduated from Sakarya University computer engineering department in 2016. His areas of research interests programing with artificial intelligence, architecture of microservices and devops.

Utku Köse received his Bachelor's degree from Gazi University Computer Education Department (2008). He complates his Master's degree from Afyon Kocatepe University - Computer Engineering Department (2010). And he gets title from Selcuk University - Computer Engineering Department of Ph.D. (2017). He works as an Associate Professor at Süleyman Demirel University. Dr. Köse's general expertise and research topics include; mainly Artificial Intelligence, Machine Ethics, Artificial Intelligence Security, Biomedical Applications, Optimization, Chaos Theory, Distance Education, E-Learning and related technologies, Computer Education and Computer Science. 